\title{
Plasma Electrolytic Oxidation of Binary Al-Sn Alloys
}

\author{
Y. Gencer*, M. Tarakci, A.E. Gulec and Z. Cagatay Oter \\ Gebze Institute of Technology, Department of Materials Science and Engineering, 41400 Gebze, Kocaeli, Turkey
}

Binary Al-Sn (1, 2, 4, 6, 8 at.\% Sn) synthetic alloys were prepared under vacuum-atmosphere controlled furnace. The Al-Sn alloys were coated by plasma electrolytic oxidation technique for 120 min in aqueous electrolyte containing sodium silicate and potassium hydroxide using the same electrical parameters. The microstructure, surface roughness, phase content and chemical composition of the coatings were characterized by scanning electron microscopy, profilometry and X-ray diffractometry. The coating became porous while coating thickness and surface roughness decreased, with increasing amount of Sn content in Al-Sn alloys. The coating was not formed on the Al-Sn alloy with 8 at.\% Sn. Plasma electrolytic oxidation coatings were composed of mainly mullite $\left(3 \mathrm{Al}_{2} \mathrm{O}_{3} \cdot 2 \mathrm{SiO}_{2}\right), \gamma-\mathrm{Al}_{2} \mathrm{O}_{3}$ and $\alpha-\mathrm{Al}_{2} \mathrm{O}_{3}$ up to 4 at. $\%$ Sn. The $\alpha-\mathrm{Al}_{2} \mathrm{O}_{3}$ phase formed as precipitate in the inner region of the coating and its amount decreased with $\mathrm{Sn}$ amount in the $\mathrm{Al}-\mathrm{Sn}$ alloys. The $\mathrm{SnO}_{2}$ phase was only detected in the coating of Al-6Sn alloy. Scanning electron microscopy - energy dispersive X-ray spectroscopy results showed that the traces of $\mathrm{Sn}$ were evident in the oxide coating along with $\mathrm{Al}, \mathrm{O}, \mathrm{Si}, \mathrm{Na}$, and $\mathrm{K}$. The increasing addition of $\mathrm{Sn}$ in the alloys resulted in reduction of the overall microhardness of the coating with decreasing manner from dense inner region to the surface of the coatings.

DOI: 10.12693 /APhysPolA.125.659

PACS: 81.15.-z, 81.05.Bx

\section{Introduction}

Aluminum and its alloys are extensively used as engineering materials because of their important properties of high strength/density rate and recyclability [1, 2]. Al alloys containing tin are one of the important Al alloys for many industrial application such as plain bearings, pistons and cylinder liners in internal combustion engines, cylinder blocks as tribological and mechanical properties are enhanced by addition of $\mathrm{Sn}$ to $\mathrm{Al}$ alloys to some extent $[3-5]$. However, due to the soft nature of Sn, the alloys are lack of ability to support the heavy loads and having low scratch resistance [6].

Anodic oxidation is one of the most applied coating methods for aluminum and its alloys to improve their properties $[7,8]$. However, scratch resistance, hardness and thickness values of coatings obtained by anodic oxidation are not sufficient and electrolytes used for this process are not eco-friendly [8].

PEO is a recently developed plasma enhanced electrochemical surface modification method used to produce oxide based ceramic coatings with superior wear and corrosion resistance, electrical and thermal properties on light metals and their alloys such as $\mathrm{Al}, \mathrm{Ti}, \mathrm{Mg}$, Zr [9-12]. The properties of coatings obtained by PEO method depend on many process parameters such as current density, electrolyte composition, process time and chemical composition of substrate [10, 13-15]. One of the most important parameters which affect the PEO coating properties is the chemical composition of the substrate. Although, there are extensive studies on the application of PEO on different $\mathrm{Al}$ alloys including Sn con-

*corresponding author; e-mail: gencer@gyte.edu.tr taining Al alloys to investigate the substrates' chemical composition effect, there are limited systematical studies to reveal the individual effects of $\mathrm{Al}$ alloying elements on the PEO properties [16]. These systematical studies showed that the PEO coating thickness, microstructure, surface roughness, microhardness and phase compositions of the coating were strongly influenced by the alloying elements' amount in the binary $\mathrm{Al}-\mathrm{M}(\mathrm{M}=\mathrm{Mg}$, $\mathrm{Zn}, \mathrm{Cu}, \mathrm{Si})$ [1, 17-19]. To our knowledge apart from the limited Sn containing Al alloys, there is not any enlightening systematical study to reveal the individual effect of $\mathrm{Sn}$ on the properties of PEO coating of Al.

Hence, in this study, synthetic binary Al-Sn alloys with different Sn contents were prepared as substrate material and coated by $\mathrm{PEO}$ process in order to investigate specific effect of Sn on the coatings properties.

\section{Experimental}

Pure aluminum (99.96\%) and pure tin (99.9\%) were used to prepare binary Al-Sn alloys containing 1, 2, 4, 6,8 at.\% Sn and these alloys were designated as Al-1Sn, $\mathrm{Al}-2 \mathrm{Sn}, \mathrm{Al}-4 \mathrm{Sn}, \mathrm{Al}-6 \mathrm{Sn}$ and $\mathrm{Al}-8 \mathrm{Sn}$, respectively. Al-Sn ingots with dimensions of $25 \mathrm{~mm} \times 50 \mathrm{~mm} \times 100 \mathrm{~mm}$ were prepared by melting in vacuum-atmosphere controlled furnace and casting into copper mold. The Al-Sn ingots were sliced to obtain substrates for $\mathrm{PEO}$ process with the dimensions of $25 \mathrm{~mm} \times 50 \mathrm{~mm} \times 5 \mathrm{~mm}$. The surfaces of the substrates were ground by using $80-1200$ grit $\mathrm{SiC}$ papers and polished by using $3-1 \mu \mathrm{m}$ alumina containing solution. The polished substrates were then cleaned in ultrasonic bath containing ethanol for $5 \mathrm{~min}$. The surface roughness of the uncoated substrates was measured using Veeco Dektak 8 Profilometer. The electrolyte for $\mathrm{PEO}$ process was prepared by dissolving $12 \mathrm{~g} / 1$ $\mathrm{Na}_{2} \mathrm{SiO}_{3}$ and $2 \mathrm{~g} / 1 \mathrm{KOH}$ in distilled water. The process was carried out by means of a PEO equipment with $\mathrm{AC}$ power supply in a water cooled stainless steel container. 
The temperature of the electrolyte $\left(20^{\circ} \mathrm{C}\right)$ and electrical parameters was kept constant during 120 min coating process for all samples. The coated samples were cleaned using deionized water and dried under warm air. Phase analysis of the coated Al-Sn alloys was carried out using Bruker D8 Advanced X-ray diffractometer with a $\mathrm{Cu} K_{\alpha}$ radiation, over a $2 \theta$ range from $10^{\circ}$ to $90^{\circ}$. A further XRD study was carried out by grinding and removing half of the oxide coating from the surface of Al-1Sn alloy. The profilometer was employed to determine surface roughness of each coated sample. The surface and cross-section of the PEO coated samples were examined by scanning electron microscope Philips XL 30 (SEM). After surface examination, the samples were cut into two pieces for cross-sectional microstructure examination, chemical analysis, and microhardness measurements. The cut pieces were mounted in epoxy resin, ground and polished to expose their cross-sections. Vickers hardness measurements were carried out using Mitutoyo MicroWizhard by application of $30 \mathrm{~g}$ on the cross-section of the coating through the coating thickness.

\section{Results}

The XRD patterns obtained from the surface of PEO coatings of Al-Sn alloys and from the ground surface of $\mathrm{Al}-1 \mathrm{Sn}$ alloy $(\mathrm{Al}-1 \mathrm{Sn}-\mathrm{G})$ were given in Fig. 1. The surface XRD results show that all coatings consist of mullite $\left(\mathrm{Al}_{6} \mathrm{Si}_{2} \mathrm{O}_{13}\right)$ and $\gamma-\mathrm{Al}_{2} \mathrm{O}_{3}$ phases. The formation of $\alpha-\mathrm{Al}_{2} \mathrm{O}_{3}$ phase was seen only in $\mathrm{Al}-1 \mathrm{Sn}-\mathrm{G}$ pattern. Intensity of mullite phase increases with the increasing amount of Sn in the substrate. The XRD pattern of all coatings except Al-1Sn clearly shows amorphous structure formation with increasing manner with Sn amount in the alloys. The $\mathrm{SnO}_{2}$ phase was only detected in the pattern of $\mathrm{Al}-6 \mathrm{Sn}$ alloy. In addition to these phases, the presence of $\mathrm{Al}$ originated from the substrate was also evident in XRD pattern for all alloys.

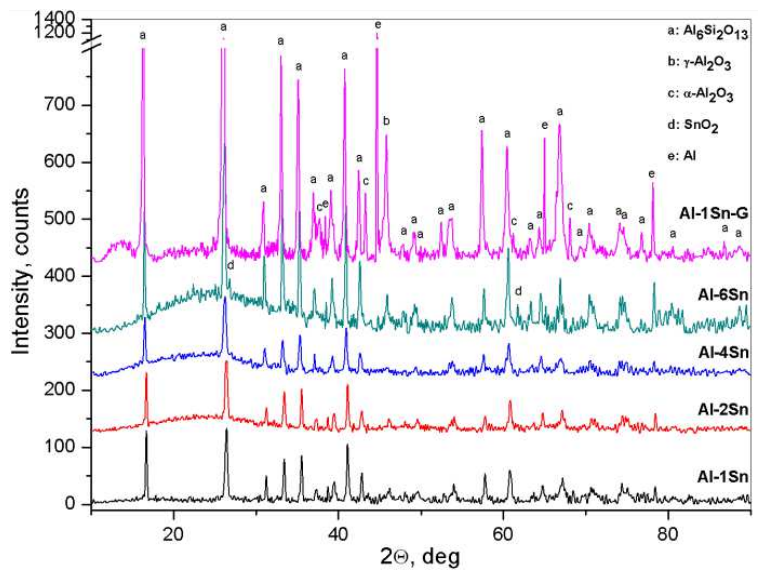

Fig. 1. XRD patterns obtained from the surface of all PEO coatings and ground surface coating of Al-1Sn.

The surface SEM micrographs of PEO coated Al-Sn (1-6 at.\%) alloys are shown in Fig. 2. The surface of the coated surfaces is composed of various sized spherical shaped porous and hollow hemisphere features and the smaller sized spherical features with partly sponge-like rough appearance. There are materials deposited in the center, which are defined as the plasma channel, of hemisphere features [20]. Some regions of the coating surface have a relatively glassy appearance with some cracks and porosities. The glassy appearance of the surface is much dominant on the surface of Al-6Sn alloys with decreasing sponge-like nature (Fig. 2d).

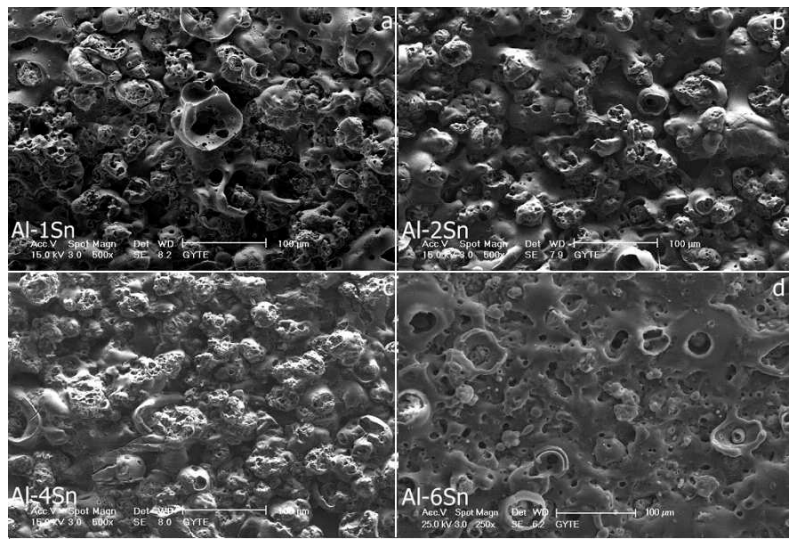

Fig. 2. The surface SEM micrographs of the PEO coated Al-Sn alloys: (c) $\mathrm{Al}-4 \mathrm{Sn}$, (d) Al-6Sn.
(a) $\mathrm{Al}-1 \mathrm{Sn}$,
(b) $\mathrm{Al}-2 \mathrm{Sn}$,
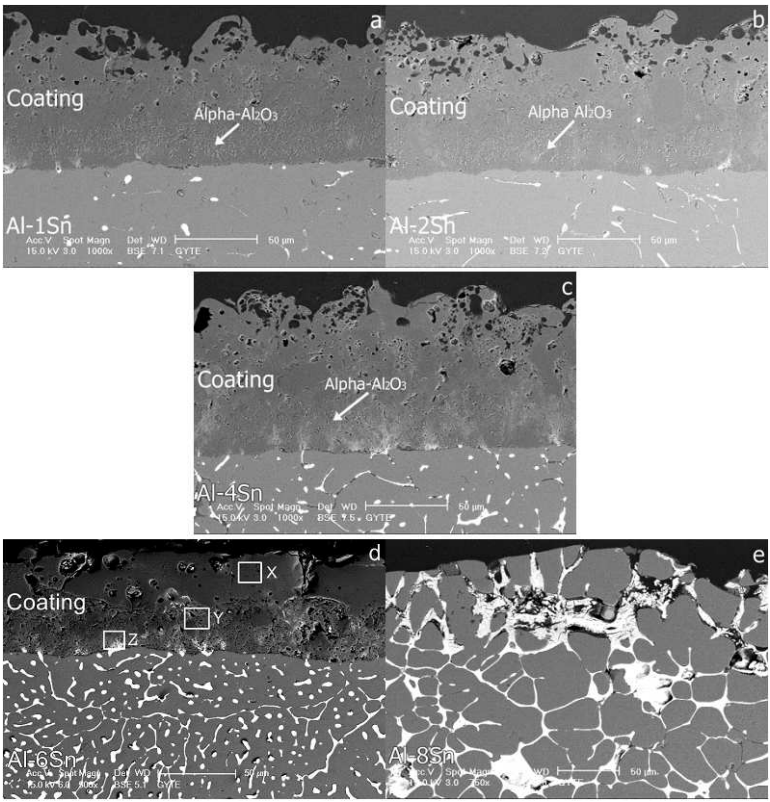

Fig. 3. The cross-sectional micrographs of the PEO coated Al-Sn alloys: (a) Al-1Sn, (b) Al-2Sn, (c) Al-4Sn, (d) Al-6Sn, (e) Al-8Sn.

Figure 3 shows the cross-sectional SEM images of PEO coated Al-Sn (1-8 at.\%) alloys. The oxide coatings were synthesized on Al-Sn alloys with 1-6 at.\% Sn (Fig. 3a-d) but coating was not evident on the surface of $\mathrm{Al}-8 \mathrm{Sn}$ alloy (Fig. 3e). The coatings adhered to the substrates very 
well. Two main coating regions are seen on these micrographs. The outer region is porous for $\mathrm{Al}-1 \mathrm{Sn}, \mathrm{Al}-2 \mathrm{Sn}$, $\mathrm{Al}-4 \mathrm{Sn}$ alloys (Fig. 3a-c) while it is glassy and dense in nature for Al-6Al alloy (Fig. 3d). The inner region of the coating with some precipitates, which were reported as $\alpha-\mathrm{Al}_{2} \mathrm{O}_{3}$ phase for other $\mathrm{Al}$ alloys in literature [1, 17], is relatively denser for $\mathrm{Al}-1 \mathrm{Sn}, \mathrm{Al}-2 \mathrm{Sn}, \mathrm{Al}-4 \mathrm{Sn}$ alloys while the porosity increases with increase of Sn content in the substrates. The amount of precipitates tends to decrease with increasing $\mathrm{Sn}$ content in the alloys. The precipitates had not formed but instead, porous inner region was evident for the coating of Al-6Sn alloy.

SEM-EDS analysis results obtained from the marked areas of $X, Y, Z$ on the cross-section of coating of Al-6Sn shown in Fig. 3d were given in Fig. 4. These spectra show that the coatings contain $\mathrm{Al}, \mathrm{Sn}, \mathrm{O}, \mathrm{Si}, \mathrm{Na}$, and $\mathrm{K}$. Amount of aluminum approximately is the same both in glassy outer ( $\mathrm{X}$ in Fig. 3d) and in porous inner regions ( $\mathrm{Y}$ in Fig. 3d) of the coating while amount of oxygen decreased in the inner region of the coating. The amount of Si was similar in outer and inner regions of the coating. The amount of Sn was evident in the inner region while it was not detected in the outer region of the coating. The spectrum shows that the region with light gray color ( $\mathrm{Z}$ in Fig. 3d) has more Sn content with lesser $\mathrm{O}$ content compared to region $\mathrm{Y}$ in Fig. 3d.

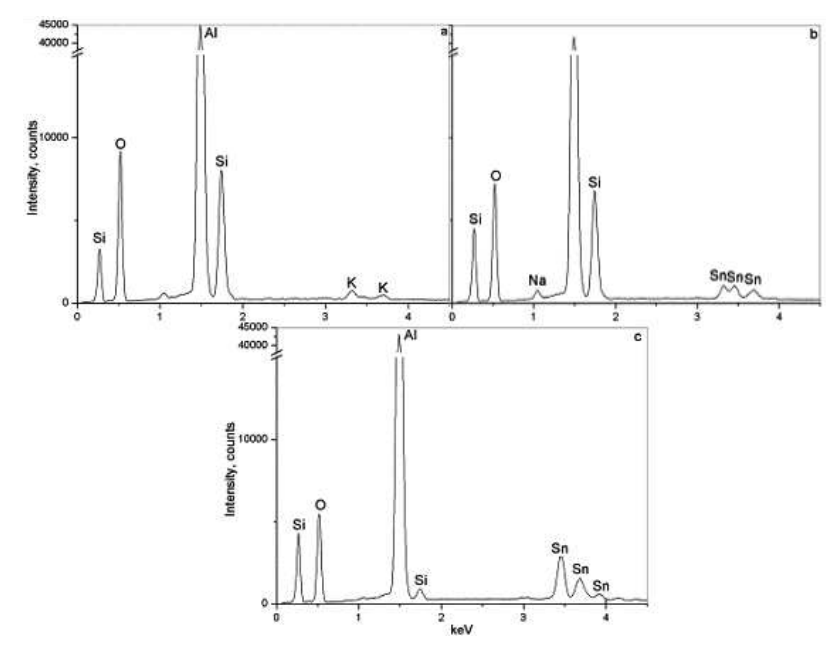

Fig. 4. Area SEM-EDS spectra of marked regions: (a) X, (b) Y and (c) Z in Fig. 3d.

The microhardness profiles from the substrate/coating interface of PEO coatings for Al-Sn alloys are shown in Fig. 5. The microhardness values of the coatings of alloys with 1-4 at.\% Sn measured at the region close to substrates firstly increase $(28-35 \mu \mathrm{m}$ to the interface), then decrease with distance towards the surface of the coatings. The highest microhardness value was measured as $1957 \mathrm{HV}$ for the coating of Al-1Sn alloy. The addition of Sn to the substrate results in lower microhardness values in coatings. It is also noted that the microhardness values decrease from the interface towards the coating surface without any increase for Al-6Sn alloy.

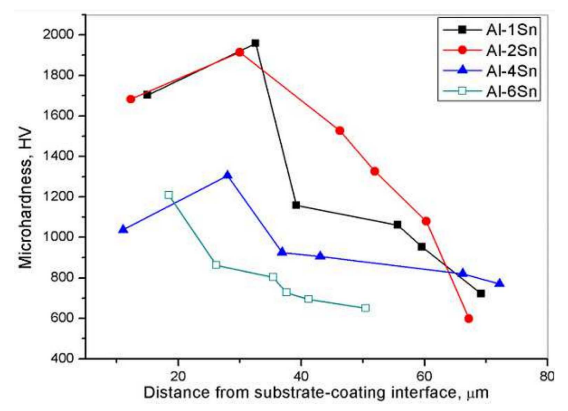

Fig. 5. The microhardness profiles from the substrate/coating interface of PEO coatings for Al-Sn alloys.

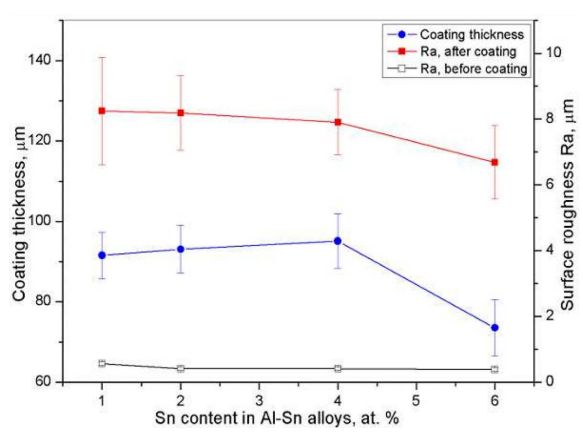

Fig. 6. The change in PEO coating thickness and surface roughness $\left(R_{\mathrm{a}}\right)$ with $\mathrm{Sn}$ content in $\mathrm{Al}-\mathrm{Sn}$ alloys.

Figure 6 reveals the average thickness values determined from the cross-sectional views of the SEM micrographs. It can be seen that coating thickness values slightly increased for the alloys containing Sn up to 4 at.\% from $91 \mu \mathrm{m}$ to $95 \mu \mathrm{m}$. The coating thickness decreased to $73 \mu \mathrm{m}$ for Al-6Sn alloy while the coating was not formed on Al-8Sn alloy. Figure 6 also illustrates surface roughness $\left(R_{\mathrm{a}}\right)$ of the coating vs. the amount of $\mathrm{Sn}$ in Al-Sn substrates samples. The surface roughness of the uncoated samples was about $0.4 \mu \mathrm{m}$. Surface roughness value of the coating decreased with increasing $\mathrm{Sn}$ content in Al-Sn alloys. The average surface roughness value of the coating is $8.2 \mu \mathrm{m}$ for $\mathrm{Al}-1 \mathrm{Sn}$ and it decreases to $6.7 \mu \mathrm{m}$ for $\mathrm{Al}-6 \mathrm{Sn}$.

\section{Discussion}

The experimental results showed that oxide based ceramic coating was successfully synthesized on $\mathrm{Al}-\mathrm{Sn}$ alloys containing Sn up to 6 at.\% while coating did not formed on Al-8Sn alloy. The detailed evaluation of the experimental results shows that the presence of $\mathrm{Sn}$ in the alloys affects the formation and their amounts of the phases formed in the coating. The oxide based ceramic coating contained mainly mullite phase on the outer loose 
region of the coating while the inner denser region contained $\gamma-\mathrm{Al}_{2} \mathrm{O}_{3}$ and $\alpha-\mathrm{Al}_{2} \mathrm{O}_{3}$ phases for the alloys containing $\mathrm{Sn}$ up to 4 at.\%. The mullite phase was formed due to the existence of sodium silicate in the electrolyte and the complex reactions during the PEO process.

The amorphous phase formation is attributed to the existence of $\mathrm{Sn}$ in the substrates and consequently $\mathrm{Sn}-\mathrm{O}$ in the coating. Probably the existence of $\mathrm{Sn}-\mathrm{O}$ in the oxide coating changes the melting and the crystallization temperature of mixture of mullite-Sn-O. This is more clearly evident for the coating surface on $\mathrm{Al}-6 \mathrm{Sn}$ that it has coating with dense glassy layer containing gas porosities from the cross-section image of the coating (Fig. 3d) and spread melted-solidified glassy appearance from the surface SEM image (Fig. 2d).

The similar crystalline-amorphous mullite formation mechanism was also reported for PEO coated $\mathrm{Al}-\mathrm{Mg}$ binary alloys [1]. The existence of $\mathrm{Sn}$ was also evident in the inner region of the coating in the form of $\mathrm{SnO}_{2}$ according to the evaluation of XRD and SEM-EDS results of $\mathrm{Al}-6 \mathrm{Sn}$ alloys. This $\mathrm{SnO}_{2}$ was also seen clearly as light gray region in the oxide coating cross-sectional SEM images of $\mathrm{Al}-1 \mathrm{Sn}, \mathrm{Al}-2 \mathrm{Sn}$, and $\mathrm{Al}-4 \mathrm{Sn}$. But, this phase was not detected by XRD analysis of these alloys' coatings. This may be because of the low amount Sn in Al-1Sn and thicker coating on $\mathrm{Al}-4 \mathrm{Sn}$ alloys. The presence of $\mathrm{SnO}_{2}$ phase in the coating produced by $\mathrm{PEO}$ on $\mathrm{Al}-20 \mathrm{wt} \% \mathrm{Sn}$ substrate was also reported in the literature [16].

The existence of $\alpha-\mathrm{Al}_{2} \mathrm{O}_{3}$ phase in the form of precipitates was seen for Al-Sn with 1-4 at.\% Sn but not seen for Al-6Sn. It was similarly reported that the inner dense region of the $\mathrm{PEO}$ coating on aluminum alloys is composed of $\alpha-\mathrm{Al}_{2} \mathrm{O}_{3}[1,17]$. However, the presence of this phase was not detected by surface XRD examination but further XRD examination from the ground surface revealed this phase's existence in the coating. Absence of this phase in the direct surface XRD analysis is either because of the high thickness of the coating or very low amount of the phase in the oxide coating. In the literature, it was reported that firstly $\gamma-\mathrm{Al}_{2} \mathrm{O}_{3}$ formation take place and this phase transforms to $\alpha-\mathrm{Al}_{2} \mathrm{O}_{3}$ at high temperatures. This is because the increase in thickness of PEO coating result in decrease in heat transfer rate and consequently it promotes the transformation from $\gamma-\mathrm{Al}_{2} \mathrm{O}_{3}$ to $\alpha-\mathrm{Al}_{2} \mathrm{O}_{3}$ [21]. However, although the thickness of coating is nearly the same for the alloys containing up to 4 at.\% $\mathrm{Sn}$, the amount of $\alpha-\mathrm{Al}_{2} \mathrm{O}_{3}$ precipitates diminishes with increasing $\mathrm{Sn}$ amount in the substrates. The presence of higher content of Sn either increases the cooling rate by increasing the porosity and hence increasing the infiltrated amount of cold electrolyte through plasma channels or Sn mixes with $\mathrm{Al}-\mathrm{O}$ in the oxide coating and changes phase transformation kinetics from $\gamma-\mathrm{Al}_{2} \mathrm{O}_{3}$ to $\alpha-\mathrm{Al}_{2} \mathrm{O}_{3}$.

The microhardness measurements illustrate that the dense region containing $\alpha-\mathrm{Al}_{2} \mathrm{O}_{3}$ precipitates has microhardness values of approximately 1300-1950 HV (Fig. 5). The microhardness values of the coatings of alloys with
1-4 at.\% Sn were measured at the region close to substrates with firstly increasing, then decreasing manner with distance towards the surface of the coatings. The addition of Sn to the substrate results in lower overall microhardness values in all coatings. It is noted that the microhardness values decreases from the interface towards the coating surface without any increase for $\mathrm{Al}-6 \mathrm{Sn}$. The lower microhardness values in the area close to the substrate/coating interface are because of the presence of $\mathrm{Sn}-\mathrm{O}$ and the absence of $\alpha-\mathrm{Al}_{2} \mathrm{O}_{3}$.

This may be attributed to the deficit of oxygen which resulted in non-stoichiometric $\mathrm{Al}_{x} \mathrm{O}_{y}$ phase's formation (Fig. 4). It should also be noted that the increase of $\mathrm{Sn}$ in the coating not only prevents $\alpha-\mathrm{Al}_{2} \mathrm{O}_{3}$ formation, it also reduces the overall microhardness values since the hardness of $\mathrm{Sn}-\mathrm{O}$ is very low. The slight increase in thickness of the coatings of $\mathrm{Al}-\mathrm{Sn}(1-4$ at.\% S) alloys may be attributed to the slight increase in porosity increase in the coating due to the increase in Sn content.

However, the decrease of the coating thickness for Al-6Sn may be attributed to the inhibiting of the oxidation of aluminum by increase of the content of $\mathrm{Sn}$ in the alloy (Fig. 3d). Hence, the oxide coating was not formed due to the high content of $\mathrm{Sn}$ in the alloys for Al-8Sn (Fig. 3e). As it should also be noted that existence of $\mathrm{Sn}$ in the matrix as a continuous network along grain boundaries prevents the oxide based dielectric film which is essential criteria for plasma formation.

\section{Conclusion}

1. The thickness is almost the same for the coatings up to 4 at.\% Sn containing alloys and then it decreases for further Sn addition while no coating was evident for $\mathrm{Al}-8 \mathrm{Sn}$.

2. The coatings consist of mullite and $\gamma-\mathrm{Al}_{2} \mathrm{O}_{3}$ phases. The presence of $\alpha-\mathrm{Al}_{2} \mathrm{O}_{3}$ was evident for alloys with Sn content less than 6 at.\%. The formation of $\alpha-\mathrm{Al}_{2} \mathrm{O}_{3}$ phase was hindered by the increase of $\mathrm{Sn}$ content in the alloys. The $\mathrm{SnO}_{2}$ phase was only detected in the pattern of $\mathrm{Al}-6 \mathrm{Sn}$ alloy.

3. The microhardness values of the coatings of alloys with 1-4 at.\% Sn measured at the region close to substrates firstly increase, then decrease with distance from substrate/coating interface towards the surface of the coatings. The addition of Sn reduces the average microhardness values of the coatings on Al-Sn alloys.

4. The traces of $\mathrm{Sn}$ were evident in the oxide coating along with $\mathrm{Al}, \mathrm{O}, \mathrm{Si}, \mathrm{Na}$, and $\mathrm{K}$.

5. The Sn content increases the porosity in the coating and it increases the amorphous phase formation on the surface of the coating. The surface roughness decreases with increasing Sn content in the alloys. 


\section{Acknowledgments}

The author expresses his thanks to technicians Adem Sen and Ahmet Nazım for their kind assistance during XRD and SEM experimental studies.

\section{References}

[1] M. Tarakci, Mater. Character. 62, 1214 (2011).

[2] F.T. Xu, Y. Xia, G. Li, Appl. Surf. Sci. 255, 9531 (2009).

[3] B.K. Prasad, K. Venkateswarlu, O.P. Modi, A.H. Yegneswaran, J. Mater. Sci. Lett. 15, 1773 (1996).

[4] F.A. Davis, T.S. Eyre, Tribol. Int. 27, 171 (1994).

[5] H. Torabian, J.P. Pathak, S.N. Tiwari, Wear 177, 47 (1994).

[6] T.V. Rajan, Tribol. Trans. 36, 121 (1995).

[7] Y. Ma, Y.X. Zhou, G.E. Thompson, M. Curioni, T. Hashimoto, P. Skeldon, P. Thomson, M. Fowles, J. Electrochem. Soc. 158, C17 (2011).

[8] M. Yoshimoto, M.Y. Morizono, S. Tsurekawa, T. Baba, J. Ceram. Soc. Japan 120, 276 (2012).

[9] Y. Gencer, M. Tarakci, S. Cengiz, J. Fac. Eng. Archit. Gazi University 26, 851 (2011).

[10] A.L. Yerokhin, X. Nie, A. Leyland, A. Matthews, S.J. Dowey, Surf. Coat. Technol. 122, 73 (1999).

[11] Z.P. Yao, Z.H. Jiang, X.H. Wu, X.T. Sun, Z.D. Wu, Surf. Coat. Technol. 200, 2445 (2005).
[12] E.E. Demirci, E. Arslan, K.V. Ezirmik, O. Baran, Y. Totik, I. Efeoglu, Thin Solid Films 528, 116 (2013).

[13] S.V. Gnedenkov, O.A. Khrisanfova, A.G. Zavidnaya, S.L. Sinebrukhov, A.N. Kovryanov, T.M. Scorobogatova, P.S. Gordienko, Surf. Coat. Technol. 123, 24 (2000).

[14] T.B. Wei, F.Y. Yan, J. Tian, J. Alloys Comp. 389, 169 (2005).

[15] G.L. Yang, X.Y. Lu, Y.Z. Bai, Z.S. Jin, Chin. Phys. Lett. 18, 1141 (2001).

[16] Z.J. Wang, L.N. Wu, Y.L. Qi, Z.H. Jiang, Appl. Surf. Sci. 256, 3443 (2010).

[17] Y. Gencer, A.E. Gulec, J. Alloys Comp. 525, 159 (2012).

[18] A.E. Gulec, in: Materials Science and Engineering, Gebze Institute of Technology, Gebze, Kocaeli, Turkey 2012, p. 40.

[19] A.O. Devecili, in: Materials Science and Engineering, Gebze Institute of Technology, Gebze, Kocaeli, Turkey 2009, p. 30.

[20] G. Sundararajan, L.R. Krishna, Surf. Coat. Technol. 167, 269 (2003).

[21] S.G. Xin, L.X. Song, R.G. Zhao, X.F. Hu, Surf. Coat. Technol. 199, 184 (2005). 